Aim of the study: To present the characteristics and clinical outcomes in 94 patients with mucinous breast cancer treated at the Oncology Centre in Krakow between 1952 and 2002

Material and methods: Stage I or II carcinomas were found in 66 patients (69.4\%) of the presented group and in the remaining 28 patients $(29.8 \%)$ stage III disease was diagnosed. In 27 cases regional lymph nodes were involved. All patients had been treated with surgery: mastectomy (90 patients) or breast-conserving treatment (4 patients). Radiotherapy was administered in 14 patients, adjuvant chemotherapy in 14 patients, and endocrine therapy in 39 patients.

Results: The maximum follow-up was 257 months. Ten-year survival was as follows: $75.7 \%$ (overall survival), $82.5 \%$ (disease-free survival). During the follow-up, 4 patients developed local recurrence, 5 patients developed metastases. Second primary cancer was found in 8 patients.

Conclusions: The presented results confirm the good prognosis in patients treated for mucinous breast cancer. The diagnosis of early-stage breast cancer based on mammography can allow breast-conserving treatment.

Key words: mucinous breast cancer, mastectomy, breast-conserving treatment, second primary cancer.

Contemp Oncol (Pozn) 2014; 18 (2): 120-123 DOI: $10.5114 /$ wo.2014.42727

\section{Mucinous breast cancer - clinical characteristics and treatment results in patients treated at the Oncology Centre in Kraków between 1952 and 2002}

\author{
Beata Sas-Korczyńska', Jerzy Mituśn ${ }^{2}$, Andrzej Stelmach², Janusz Ryśs \\ Anna Majczyk ${ }^{1}$
}

\begin{abstract}
${ }^{1}$ Clinic of Oncology - Department of Breast and Chest Cancer, Centre of Oncology Maria Sklodowska-Curie Memorial Institute, Krakow Branch, Poland

${ }^{2}$ Department of Oncological Surgery, Centre of Oncology - Maria Sklodowska-Curie Memorial Institute, Krakow Branch, Poland

${ }^{3}$ Department of Tumor Pathology, Centre of Oncology - Maria Sklodowska-Curie
\end{abstract}

Memorial Institute, Krakow Branch, Poland

\section{Introduction}

Pure mucinous breast cancer represents approximately 1-4\% of all malignant breast carcinomas. This type of cancer is most commonly diagnosed in women aged 55-60 and above [1-9].

The microscopic assessment of the cancer presents cell clusters floating in mucus lakes, separated by thin epithelial membranes containing capillaries. The clusters differ in quantity and in some cases tend to form tubular structures. The cancer cells indicate low nuclear atypia. The above characteristics are dominant in $90 \%$ of pure mucinous cancer cases. In mixed form, the ductal carcinoma component is present additionally. Mucinous breast cancer has been defined as low grade cancer with the presence of hormone receptors (oestrogen in 91-94\%, progesterone in 79-81\%) and lack of HER2 amplification. Lymph node metastases are rarely seen clinically in this form of cancer. All the factors are linked with favourable prognosis [1, 2, 4, 5, 9, 10].

Mucinous breast cancer is usually diagnosed in relatively early stages of the disease $[2,6]$. In approximately $50 \%$ of patients, physical examinations indicate the presence of a well-circumscribed tumour in the breast. For the remaining $50 \%$ of patients, in whom clinical symptoms are not present, the form of cancer is diagnosed during screening mammography. Its image resembles benign lesions. In such cases histopathological examinations are decisive $[5,11,12]$.

In comparison to the infiltrating ductal carcinoma of the breast, pure mucinous breast carcinoma portends a less aggressive clinical course. Ten-year disease-free survival rates are over 90\% [13-15].

\section{Aim of the study}

The purpose of this study is to present the characteristics and the results of the treatment of patients suffering from pure mucinous breast carcinoma treated over a 50-year period at the Oncology Centre in Kraków.

\section{Material and methods}

In the period 1952 to 2002, 94 patients were diagnosed with pure mucinous breast carcinoma at the Oncology Centre in Kraków. These cases represented $0.7 \%$ of all $(13,571)$ patients treated for breast cancer in this period. 
Table 1 presents the clinical characteristics of the discussed group of patients.

The age ranged from 32 up to 85 years and was on average 64 years (median age: 67). Cancer symptoms (presence of a tumour in the breast) in 83 patients (88.3\%) preceded recognition by 1-24 months and lasted for approximately 6 months. In 11 patients (11.7\%) breast cancer was recognised by prophylactic exams.

The extent of cancer presented in the study was based on the presently adopted TNM classification of breast cancer at the time of treatment planning.

The majority of patients (60 patients $-63.8 \%$ ) were diagnosed with stage $\mathrm{T} 2$ cancer.

In 67 (71.3\%) patients, no lymph node metastases were noted. For the remaining 27 patients (28.7\%), metastases of lymph nodes were indicated: 1-3 lymph nodes in $15 \mathrm{pa}$ tients, 4 or more in 12 patients.

Clinical staging was defined as follows: stage I - $15 \mathrm{pa}-$ tients (16\%), stage $\mathrm{II}-51$ patients $(53.4 \%)$, stage $I I-28$ patients $(29.8 \%)$.

Table 2 presents the treatment methods.

All the patients suffering from mucinous carcinoma received primary surgical treatment. In 90 patients (95.7\%) a mastectomy was performed, using either Patey's method (60 patients) or Halsted's method (30 patients). In the remaining 4 patients (4.3\%), breast-conserving treatment was introduced (tumour resection and axillary lymphade-

Table 1. The clinical characteristics of 94 patients with pure mucinous breast cancer treated at the Oncology Centre in Krakow between 1952 and 2002

$\begin{array}{lcc}\text { Clinical feature } & \text { No. of patients } & \% \\ \text { primary tumour in breast (T): } & & \\ \text { T1 } & 14 & 14.9 \\ \text { T2 } & 60 & 63.8 \\ \text { T3 } & 20 & 21.3 \\ \text { stage (TNM): } & & \\ \text { I } & 15 & 16.0 \\ \text { II } & 51 & 54.3 \\ \text { III } & 28 & 29.8 \\ \text { nodal status (pN): } & & \\ \text { pN0 } & 67 & 71.3 \\ \text { pN+ } & 27 & 28.7 \\ \text { 1-3 } & 15 & 16.0 \\ \geq 4 & 12 & 12.8 \\ \end{array}$

Table 2. Treatment methods in 94 patients with pure mucinous breast cancer treated at the Oncology Centre in Krakow between 1952 and 2002

$\begin{array}{lcc}\text { Treatment methods } & \text { No. of patients } & \% \\ \text { surgery } & 94 & 100.0 \\ \text { mastectomy } & 90 & 95.7 \\ \text { Patey's method } & 60 & 63.8 \\ \text { Halsted's method } & 30 & 31.9 \\ \text { breast-conserving surgery } & 4 & 4.3 \\ \text { radiotherapy } & 25 & 26.6 \\ \text { chemotherapy } & 14 & 14.9 \\ \text { endocrine therapy } & 39 & 41.5\end{array}$

nectomy). In this group of patients post-operative, adjuvant radiation treatment was provided. Radiotherapy was performed in 25 patients (26.6\%).

Fourteen patients (14.9\%) were treated with adjuvant chemotherapy, whereas 39 patients (41.5\%) received endocrine therapy with tamoxifen.

In the follow-up period the incidence of complications and treatment failures was assessed. The presence of second primary cancers was also investigated. The 10-year overall and disease-fee survival rates were assessed. The Kaplan-Meier estimation was used for this purpose.

\section{Results}

In the studied group the follow-up lasted a maximum of 257 months (median: 106 months).

The actuarial 10-year survival rates were as follows: overall $-75.7 \%$, disease-free survival $-82.5 \%$.

Figure 1 presents the disease-free survival rates.

In the follow-up period, complications after treatment were observed in 15 patients (16\%). In 11 patients upper limb oedema on the operated side was observed. One patient $(1.1 \%)$ suffered from venous thrombosis, 3 patients (3.2\%) from endometrial hyperplasia of the uterus. All patients received systemic adjuvant treatment.

Table 3 presents the causes of treatment failures.

In 4 patients (4.3\%) local recurrences were noted within 18-43 months (approximately: 33 months) after breast cancer treatment.

The development of distant metastases was observed in 5 (5.3\%). It occurred within 5-169 months (approximately 77.8 months) after treatment. Metastases were most frequently localized in lungs (4 patients).

In 8 patients (8.5\%) second primary tumours were noted, among which 3 were localised in the opposite breast. The other localisations were: uterus (2 patients), cervix (1 patient), lung (1 patient) and non-Hodgkin's lymphoma (1 patient). The above neoplasms developed 24-126 months (approximately 76 months) after the treatment of mucinous breast carcinoma.

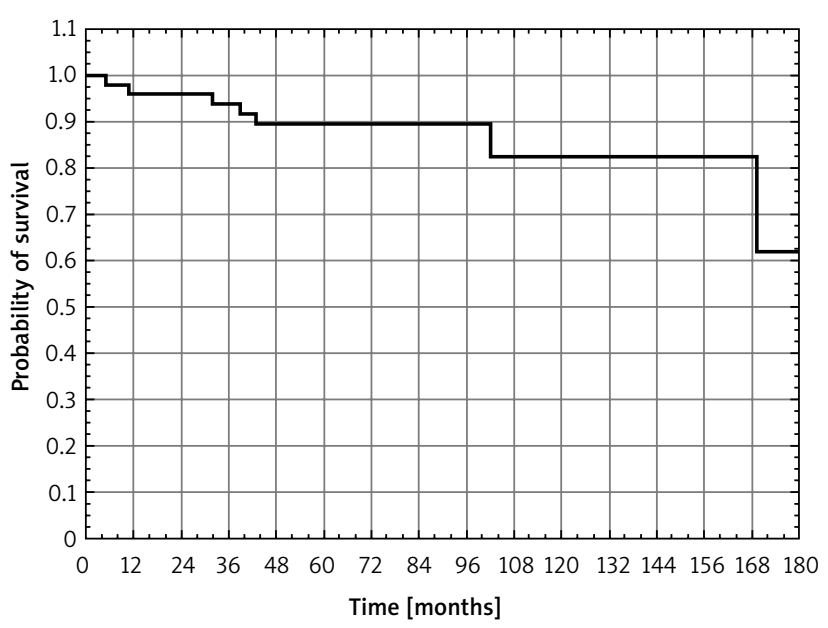

Fig. 1. The disease-freee survival in 94 patients with mucinous breast cancer 
Table 3. Failures in 94 patients with pure mucinous breast cancer treated at the Oncology Centre in Krakow between 1952 and 2002

$\begin{array}{lcc}\text { Failures } & \text { No. of patients } & \% \\ \text { local recurrence } & 4 & 4.3 \\ \text { distant metastases } & 5 & 5.3 \\ \text { lung } & 4 & 4.3 \\ \text { bones } & 1 & 1.1 \\ \text { lymph nodes } & 1 & 1.1 \\ \text { brain } & 1 & 1.1\end{array}$

\section{Discussion}

Pure mucinous breast cancer has positive prognostic features. According to the literature, 5-year and 10-year survival rates are: $77-92 \%$ and $75-89 \%$ (overall), and 7691\% and $74-93 \%$ (disease-free) [2, 4, 12, 16, 17].

The obtained results are comparable to the above. Tenyear survival rates were: $75.7 \%$ (overall) and $82.5 \%$ (disease-free survival).

In approximately $50 \%$ of the patients, mucinous breast carcinoma is diagnosed by palpation, whereas in asymptomatic cases the cancer is diagnosed after mammographic screenings [11, 12].

In the studied material, for the majority of patients ( 83 from $94-88.3 \%$ ) the main symptom of the cancer was an examined tumour in the breast. In the remaining $11.7 \%$ of the patients the neoplasm was diagnosed in a mammography examination. Differences between the studied and the previously published data exist due to the fact that the studied material comes from a period of 50 years, i.e. 1952-2002. Over this period diagnosis and treatment rules changed due to the development of medicine. This can be confirmed by the observations made of the patients suffering from mucinous breast cancer treated at the Oncology Centre in Krakow in the 1952-2010 period, presented in Table 4. The period 1952-2002 is the subject of the study. In more recent years, i.e. in the period 2003-2010, mucinous breast carcinoma was detected in mammography screenings ( $34 \%$ of patients).

Mucinous breast carcinoma is most often diagnosed in older patients, aged 55-60 and above $[2-9,16]$. The characteristic feature of this type of cancer is that it can be diagnosed in relatively early stages of the disease. A stage T1-2 tumour is diagnosed in $93-97 \%$ of patients, whereas the lack of metastases to lymph nodes is observed in 62$88 \%$ of patients [4, 13, 14, 16-19].

In the studied material stage T1-2 was present in $74.7 \%$ of patients, whereas the lack of metastases to lymph nodes (pNO) was observed in $71.3 \%$ of patients. In case of the presence of metastases to lymph nodes $16 \%$ of patients suffered from metastases of 1-3 lymph nodes. According to data from the relevant literature, the presence of metastases in 1-3 lymph nodes is diagnosed in $10-11 \%$ of patients suffering from mucinous breast cancer $[2,19]$.

The results of multivariate analysis presented in the literature by Di Saverio et al. and Vo et al. indicate that particularly good prognosis in patients suffering from mucinous breast cancer is associated with the following independent factors: age, tumour size, status of lymph nodes and oestrogen receptor $[2,4,14]$. The significant influence of the status of the lymph nodes on the treatment outcome was indicated in a previous publication published by our institute, in which the results of a group of patients treated in the years 1952-1979 were presented. The cancer-free survival rate drops by two-thirds with recognition of the incidence of lymph node metastases (26.7\% vs. 83.3\%) [20].

Diab et al. observed convergence between the size of the primary tumour and the status of lymph nodes in a group of 111 patients with mucinous breast cancer. In the case of tumours below $2 \mathrm{~cm}$ in size, in $90 \%$ of the patients metastases to lymph nodes were not indicated. Increase in tumour size corresponds with a decrease in the percentage of negative lymph nodes, to the extent that in the case of tumours over $5 \mathrm{~cm}$ in size it equals $56 \%$ [2]. As a result, the number of performed lymphadenectomies and the application of systemic treatment in early mucinous cancer deteriorates. The primary method of treatment in patients suffering from the studied diagnosis is surgical treatment with post-operative adjuvant treatment: radiotherapy, chemotherapy, endocrine therapy.

In the presented material 90 out of 94 patients (95.7\%) were treated with a mastectomy (Patey's method in $60 \mathrm{pa}$ tients, Halsted's method in 30 patients). In the remaining 4 patients (4.3\%) breast-conserving treatment was introduced.

According to the data from the literature breast-conserving treatment is employed in over $60 \%$ of patients suffering from mucinous breast cancer $[13,18]$. The difference with the studied material, in which this procedure involved only $4.5 \%$ of patients, could reflect the period of the study, i.e. 1952-2002. Over this period both the methods and the spectra of treatment, along with the indications, changed. This conclusion was indicated in a prior publication of the Oncology Centre, in which a mastectomy had been performed in all patients [20]. In contrast, Table 4 presents

Table 4. Frequency of breast cancer diagnosis during screening mammography and frequency of breast-conserving surgery in patients with pure mucinous breast cancer in material of the Oncology Centre in Krakow

\begin{tabular}{|c|c|c|c|}
\hline \multirow[t]{2}{*}{ No. of patients } & \multicolumn{3}{|c|}{ Period of therapy } \\
\hline & $\begin{array}{c}1952-2002 \\
\text { (present paper) }\end{array}$ & $2003-2010$ & $\begin{array}{c}\text { total } \\
1952-2010\end{array}$ \\
\hline mucinous breast cancer & 94 & 53 & 147 \\
\hline diagnosis during screening mammography & $11(11.7 \%)$ & $18(34 \%)$ & $29(19.7 \%)$ \\
\hline breast-conserving surgery & $4(4.3 \%)$ & $19(35.8 \%)$ & $23(15.6 \%)$ \\
\hline
\end{tabular}


a significant increase in the employment of breast-conserving treatment in patients with mucinous breast carcinoma during the years 2003-2010, which was 35.8\%.

The data concerning the incidence of radiotherapy indicate that it was performed in $31-90 \%$ of patients $[4,13,14$, 17]. This could be the result of the frequency of breast-conserving treatment, during which radiotherapy was an integral part. In the studied material, in which mastectomy was a dominant procedure, $26.6 \%$ of patients were treated with radiotherapy.

According to the literature, the use of adjuvant, systemic treatment is comparable with the studied material, with frequencies of $10-37 \%$ and $14.9 \%$ (chemotherapy), and 33-84\% (endocrine therapy) [2, 4, 18, 19].

Vo et al., Li et al. and Bae et al., when comparing various histological cancer types, indicated that the involvement of systemic treatment in patients with mucinous breast cancer is less frequent than in patients with ductal breast cancer $[4,13,17]$.

In the presented group of patients, 4 out of 94 (4.3\%) indicated local recurrence, whereas in 5 patients (5.3\%) the cancer spread. According to the data, local and distant failures in patients with mucinous breast cancer are rare and concern less than $5 \%$ of the patients $[4,18]$. Diab et al. and Vo et al. claim that the decisive risk factor for the development of the failures is the presence of lymph node metastases [2, 4]. Furthermore, as was indicated by Vo et al., the failures are less frequently noted in patients with mucinous breast cancer in comparison with other histological types of breast cancer [4].

The studied observations and data from the literature indicate the good prognosis in case of mucinous breast carcinoma. Mammography screenings enable cancer to be detected at an early stage, which leaves the possibility of introducing breast-conserving treatment.

The authors declare no conflict of interest.

\section{References}

1. Lakhani SR, Ellis IO, Schnitt SJ, et al. WHO Classification of tumours of the breast. In: World Health Organization Classification of Tumours. $4^{\text {th }}$ ed. International Agency for Research on Cancer, Lyon 2012.

2. Diab SG, Clark GM, Osborne CK, Libby A, Allred DC, Elledge RM. Tu mor characteristics and clinical outcome of tubular and mucinous breast carcinomas. J Clin Oncol 1999; 17: 1442-8.

3. Thurman SA, Schnitt SJ, Connolly JL, Gelman R, Silver B, Harris JR, Recht A. Outcome after breast-conserving therapy for patients with stage I or II mucinous, medullary, or tubular breast carcinoma. Int J Radiat Oncol Biol Phys 2004; 59: 152-9.

4. Vo T, Xing Y, Meric-Bernstam F, et al. Long-term outcomes in patients with mucinous, medullary, tubular, and invasive ductal carcinomas after lumpectomy. Am J Surg 2007; 194: 527-31.

5. Reimer T. Management of rare histological types of breast. Breast Care (Basel) 2008; 3: 190-6.

6. Li Cl, Uribe DJ, Daling JR. Clinical characteristic of different histologic types of breast cancer. Br J Cancer 2005; 93: 1046-52.

7. Karan B, Pourbagher A, Bolat FA. Unusual malignant breast lesion: imaging-pathological correlations. Diagn Interv Radiol 2012; 18: 270-6.
8. Cyrta J, Andreiuolo F, Azoulay S, et al. Pure and mixed mucinous carcinoma of the breast: fine needle aspiration cytology findings and review of the literature. Cytopathology 2013; 24: 377-84.

9. Laucirica R, Bentz JS, Khalbuss WE, Clayton AC, Souers RJ, Moriarty AT. Performance characteristics of mucinous (colloid) carcinoma of the breast in fine-needle aspirates: observations from the College of American Pathologists Interlaboratory Comparison Program in Nongynecologic Cytopathology. Arch Pathol Lab Med 2011; 135: 1533-8.

10. Work ME, Andrulis IL, John EM, et al. Risk factors for uncommon histologic subtypes of breast cancer using centralized pathology review in the Breast Cancer Family Registry. Breast Cancer Res Treat 2012; 134: 1209-20.

11. Dhillon R, Depree P, Metcalf C, Wylie E. Screen-detected mucinous breast carcinoma: potential for delayed diagnosis. Clin Radiol 2006; 61: 423-30.

12. Tan JZ, Waugh J, Kumar B, Evans J. Mucinous carcinomas of the breast: Imaging features and potential for misdiagnosis. J Med Imaging Radiat Oncol 2013; 57: 25-31.

13. Li Cl. Risk of mortality by histologic type of breast cancer in the United States. Horm Cancer 2010; 1: 156-65.

14. Di Saverio S, Gutierrez J, Avisar E. A retrospective review with long term follow up of 11,400 cases of pure mucinous breast carcinoma. Breast Cancer Res Treat 2008; 111: 541-7.

15. Komaki K, Sakamoto G, Sugano H, Morimoto T, Monden Y. Mucinous carcinoma of the breast in Japan: a prognostic analysis based on morphologic features. Cancer 1988; 61: 989-96.

16. Morand C, Verrièle V, Valo I, Remoue P, Paillocher N, Chassevent A. Pure mucinous carcinomas of the breast: prognostic study including DNA flow cytometry. Clin Cytom 2009; 76B: 56-62.

17. Bae SY, Choi MY, Cho DH, Lee JE, Nam SJ, Yang JH. Mucinous carcinoma of the breast in comparison with invasive ductal carcinoma: clinicopathologic characteristics and prognosis. J Breast Cancer 2011; 14: 308-13.

18. Barkley CR, Ligibel JA, Wong JS, Lipsitz S, Smith BL, Golshan M. Mucinous breast carcinoma: a large contemporary series. Am J Surg 2008; 196: 549-51.

19. Cao AY, He M, Liu ZB, et al. Outcome of pure mucinous breast carcinoma compared to infiltrating ductal carcinoma: a populationbased study from China. Ann Surg Oncol 2012; 19: 3019-27.

20. Stelmach A, Reinfuss M, Smolak K, Mitus J. Śluzowaty rak sutka. Obraz kliniczny, leczenie i rokowanie. Nowotwory 1992; 42: 151-5.

\section{Address for correspondence}

Beata Sas-Korczyńska MD, PhD

Clinic of Oncology - Department of Breast and Chest Cancer Centre of Oncology - Maria Sklodowska-Curie Memorial Institute Krakow Branch

Garncarska 11

31-115 Krakow, Poland

e-mail: z5korczy@cyf-kr.edu.pl

Submitted: 20.05 .2013

Accepted: $\quad 7.08 .2013$ 